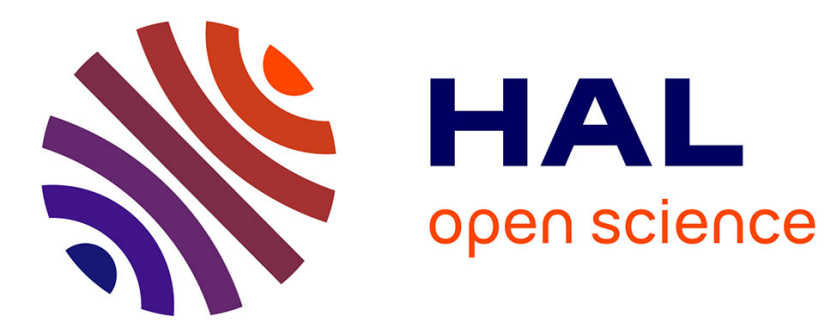

\title{
Emotion finds a way to users from designers: assessing product images to convey designer's emotion
}

Jieun Kim, Carole Bouchard, Hokyoung Ryu

\section{To cite this version:}

Jieun Kim, Carole Bouchard, Hokyoung Ryu. Emotion finds a way to users from designers: assessing product images to convey designer's emotion. Journal of Design Research, 2012, 10 (4), pp.307-323. 10.1504/JDR.2012.051171 . hal-00912865v2

\section{HAL Id: hal-00912865 \\ https://hal.science/hal-00912865v2}

Submitted on 13 May 2014

HAL is a multi-disciplinary open access archive for the deposit and dissemination of scientific research documents, whether they are published or not. The documents may come from teaching and research institutions in France or abroad, or from public or private research centers.
L'archive ouverte pluridisciplinaire HAL, est destinée au dépôt et à la diffusion de documents scientifiques de niveau recherche, publiés ou non, émanant des établissements d'enseignement et de recherche français ou étrangers, des laboratoires publics ou privés. 


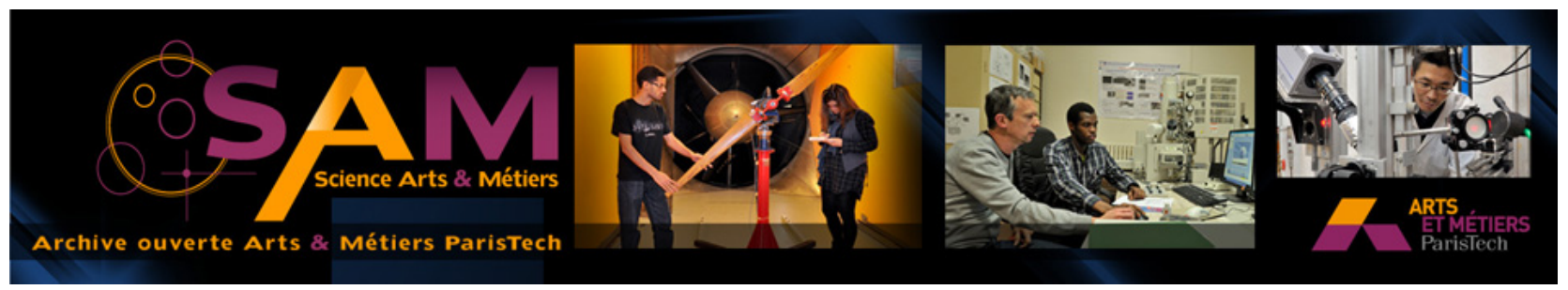

\section{Science Arts \& Métiers (SAM)}

is an open access repository that collects the work of Arts et Métiers ParisTech researchers and makes it freely available over the web where possible.

This is an author-deposited version published in: http://sam.ensam.eu

Handle ID: .http://hdl.handle.net/10985/7554

\section{To cite this version :}

Jieun KIM, Carole BOUCHARD, Hokyoung RYU, Jean-François OMHOVER, Ameziane AOUSSAT - Emotion finds a way to users from designers: assessing product images to convey designer's emotion - Journal of design research - Vol. 10, nº, p.307-323 - 2012 


\title{
Emotion finds a way to users from designers : Assessing product images to convey designer's emotion
}

\author{
Jieun Kim*, Carole Bouchard**, and Hokyoung Ryu***
}

\begin{abstract}
Address:
*Department of Industrial Engineering, Hanyang University, 222 Wangsimni-ro, Seongdong-gu, Seoul 133-791, South Korea '

**Product Design and Innovation Laboratory (LCPI), Arts et Metiers ParisTech, 151 Boulevard de l'hôpital, 75013, Paris, France '

***Department of Industrial Engineering, Hanyang University, 222 Wangsimni-ro, Seongdong-gu, Seoul 133-791, South Korea ' Product Design and Innovation Laboratory (LCPI)
\end{abstract}

\begin{abstract}
Along with a growing interest in emotional design and pleasurable products, it is necessary to understand how designers are able to maintain emotional impacts of their design solutions throughout the design process, and how these solutions can find a way to evoke the intended emotional feeling of the users. The present study first examined emotional responses to early design sketches, and how these responses could be used to check if the emotional impacts of their early sketches were observed in a combinative way of cognitive-linguistic and physiological approaches. Based on the findings of the empirical study, we further discussed how the emotional differences of product images would be generated by product forms. We figured out that good form factors of early design sketches might elicit positive feelings and high arousal states, thereby incorporating semantically meaningful features in the product images.
\end{abstract}

Keywords: product image, emotion-driven design, cognitive responses, emotional responses, physiological responses, SAM (Self-Assessment Manikin), PCA (Principal Component Analysis), GSR (Galvanic Skin Response) 


\section{Introduction}

Feelings are much like waves, we can't stop them from coming but we can choose which one to surf (Jonatan Mårtensson)

Designers are naturally and intuitively conscious of the emotional impact of their product design during the whole design process (for example, Norman 2004; Desmet and Hekkert 2007; Crilly, Moultrie, and Clarkson, 2009; Authors, 2010; Ho and Siu 2009; Cuisinier 2010). It is, by and large, touted as a good design solution when it rightfully provokes emotional responses from consumers by developing the product image that satisfies or delights them (Crilly, Moultrie, and Clarkson, 2009, p.232). This interest is partly due to industrial context to develop more pleasurable products and mostly due to increase expressivity of products for consumers. The fact that one should include users' likely emotional responses to product design has been widely acknowledged in the design community, but how this can be done is still elusive.

Indeed, Kansei engineering firstly stressed on a semantic approach to characterise perception of the product (see Nagamachi, 1989; 2001, Jindo, Hirasago, and Nagamachi, M., 1995). Since 1980s, it has evolved the semantic approach to product images and constantly influenced how to present emotiondriven product design (see Schütte, 2002). Recently, emotional design has stressed on the relationship between the users' emotional responses and product images that are arisen from both the semantic and emotional dimensions of the product (see Overbeeke and Hekkert, 1999; Desmet and Dijkhuis, 2003; Norman 2004).

That said, one of the main concerns in the current design science is to generate early sketches through understanding a link between the formal attributes of products and a set of emotional terms (See Hsiao and Wang 1999; Hsiao and Huang, 2002). In particular, the emotional values arsing from the early sketches need to be kept in the whole design process, also being observed in the final product image. However, most of previous studies have investigated how final products can provoke emotional differences and how this would be perceived by the users; very few attempts have been made on the emotional impact of early design solution (Desmet and Dijkhuis, 2003; Authors, 2011). This new approach is referred to as an "emotion-driven design" in the work of Desmet and Dijkhuis (2003), acknowledging that the development of an instrument to be sensitive to assess emotions is of great necessity.

In this context, the research questions concerned in the present study are "how designers are able to manipulate the emotional impact of their design solutions, and how these design solutions are perceived by the users?" Our research framework was then designed to establish a link between semantic and emotional responses and formal attributes of product in the early stages of design process (figure 1). Moreover, given that emotions elicited in the early representations (here, early sketches) might be hard to identify and quantify, we carried out an empirical study by employing both cognitive and physiological 
approaches to capture the emotional intents of the early sketches, and how this can be preserved in the whole design process.

Figure 1 The conceptual research framework: A designer wants to deliver her emotional intents throughout the design process.

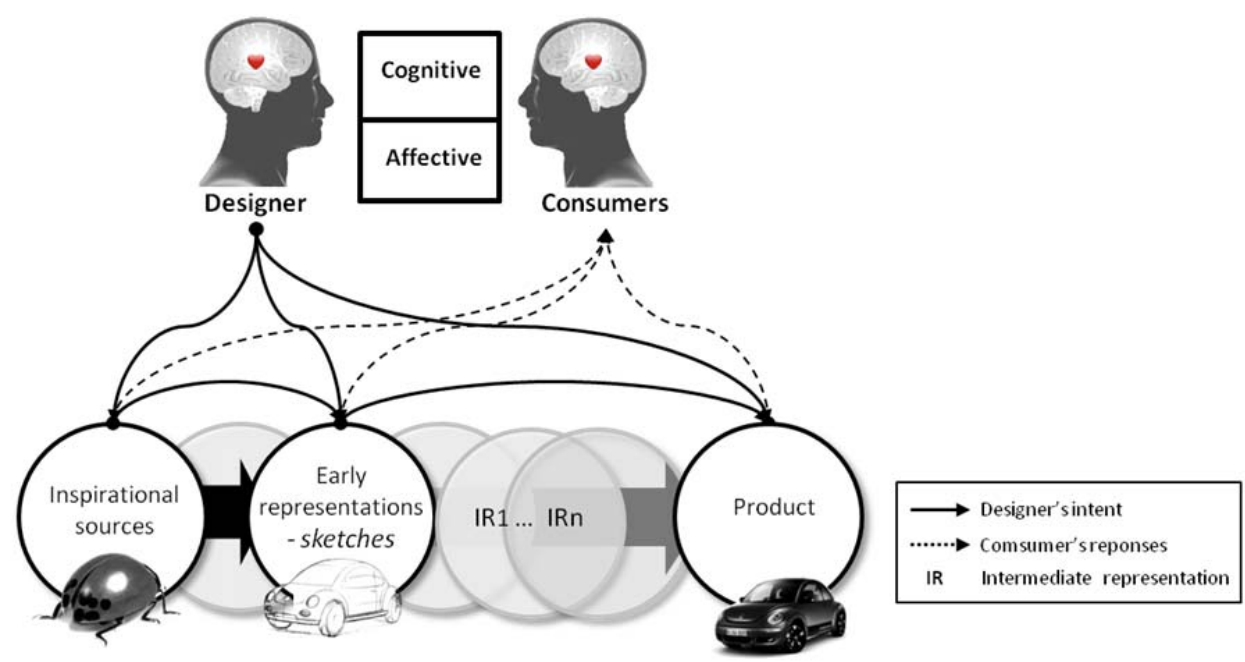

In this paper, we first present theoretic literature reviews in Section 2. Next, two hypotheses are formulated to be tested in the present study. Then, Section 3 describes the empirical study, and the results and discussion are presented in Sections 4 and 5, respectively. Finally, Section 6 presents the general conclusions and further studies.

\section{Projecting the designer's emotions onto product images: Communicating emotional intents with the users}

Synchronising emotions between the user and the designer is an emerging research topic in design science. As some pioneers in the user experience (UX) design community, such as Norman's system image (1988), have incessantly proposed new theories and methods on how to ensure the delivery of emotional intents from the designer to the user. Ho and Siu (2009) have investigated some taxonomy related to the flow of emotion between the designer and the user through design outcomes. Especially, they argued that designers inject their emotions into a product, which is referred to as "Emotionalise design". According to the affective user-designer model proposed by Helander and Khalid (2006), there are two different systems of information processing and responses: affective system and cognitive system, as shown in figure 2 . This implies that the two systems should not be separated to create the image of the product people are using, and feeling. Crilly, Moultrie, and Clarkson (2004; 2009) also developed a 
conceptual framework for establishing product images, representing the designer's intents and user responses, in terms of cognition, affect, and behaviour.

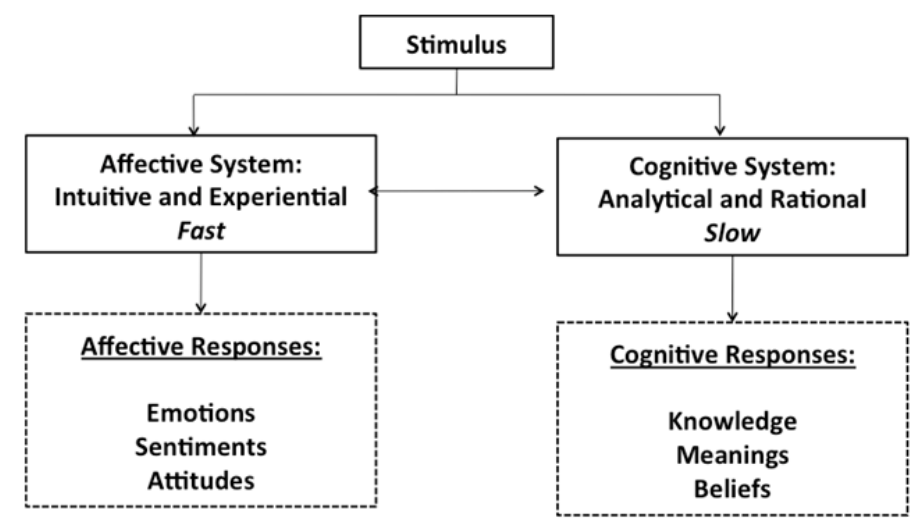

Figure 2. Coupling of affect and cognition (Helander and Khalid, 2006)

In sum, the underlying theme of the three approaches above is that emotional design (Norman, 2004) should project designer's emotional intents to the design outcomes and the users instantly perceive the designer's intents; however, there is still open to question as to how the product images can be projected on the product form, and how the designer's emotions can communicate with the users via the corresponding product form.

\subsection{Differences in semantic and emotional responses from product forms}

In the literature in design science, Bloch (1995) emphasised that product image or form plays an important role as a precursor to the users' cognitive and affective responses to a product. For instance, Chuang and Chen (2008) selected 100 armchairs as stimuli and semantically categorised them by their product forms. The method used was a semantic difference (SD) with nine scales for five bipolar adjectives: traditional-contemporary, rational-emotional, complexsimple, heavy-light, exaggerate-realistic. Hsiao and Liu (2002) also investigated a link between semantic lexicons and product images in various design sectors by using such as soft - hard, complex - simple, casual - formal, and female - male. This approach has also been validated in many design practices including automotive design (Hsiao and Wang 1999), LCD monitors, armchairs (Hsiao and Huang, 2002), door locks (Hsiao and Tsai, 2004), and coffee makers (Hsiao, Chiu, and Liu, 2010). More recently, Authors (2010) carried out a novel study to identify emotional values from perfume bottles. Their research was further advanced in order to generate product form factors based on some given emotional attributes (e.g., a rounded shape might deliver pleasant feeling). Artacho, Ballester, and Alcantara (2010) carried out an experiment with nine virtual computer loudspeakers having slightly different form attributes. They 
demonstrated that users are highly sensitive to product's form attributes and their changes can influence the user's emotional responses.

Although the studies above have been made on the high-fidelity product forms, very few have examined on early sketches or low-fidelity prototypes where designers firstly externalise their design concepts. This is very important in the sense that a first emotional impression of a product should be evolved throughout the whole design process, and as a consequence, this would ensure the delivery of emotional values to the user, at last.

\subsection{How to measure emotional differences in product images}

The modalities for expressing emotional responses are not all the same, and they can be presented in various levels such as semantic words, facial expressions, skin conduction or heart rates. Since the 1980s, many theoretical and experimental researchers from Psychology have introduced classification schemes for defining emotions (see Plutchik, 1980; Russell, 1980; Ekman, 1992). To our best knowledge, a most agreed notion is that emotions can be conceptualised along with the two dimensions: valence and arousal.

Here, a cognitive-linguistic method grounded on the semantic differential approach has been widely used to assess the emotional responses to product images. In particular, the Self Assessment Manikin (SAM) by Lang (1997) is a pictorial questionnaire in terms of arousal, valence, and dominance. In addition, lexical emotional feelings, including a list of 50 emotional reactions proposed by Geneva Emotion Research Group (1988) are often used to collect the emotional responses. However, given that emotional aspects of design are hard to express in a lexical way only, it is necessary to have more subtle modalities that can reflect the user's emotional state. Psycho-physiological methods have thus been emerging, along with the Kansei engineering field, by combining physiological techniques, such as electromyography (EMG), heart rate, electroencephalography (EEG), and so forth (Nagamachi, 2001; Schütte, 2002; Lévi, Lee, and Yamanaka, 2007; Tomino et al., 2008).

Again, a cognitive-linguistic approach is relatively simple, cheap, and quick method. Especially subjective evaluations through questionnaires and interviews are convenient and easy to administer. In addition, they can detail secondary emotions in a lexical way (Lang, 1997; Nagamachi, 2001). However, the cognitive-linguistic methods have some drawbacks. They do not enable real-time assessments and do normally capture subjective emotional responses in a holistic and reflective manner; therefore it lacks consistent evaluation thanks to respondent's different interpretations of the emotional adjectives. In addition, the use of emotional scales, which often contains a long list of emotional adjectives, might cause some fatigue for the respondents. Otherwise, a physiological approach can give real-time quantitative data and user's unconscious responses (Tran et al., 2007). However, emotional responses collected from physiological methods might not valid in that they are interfering with the designer's natural activity (SEAT Project D1.1, 2006; FEEL EUROPE, 2008) and certain 
physiological measurements (e.g., EEG) cannot be used for a long time duration (Tran et al., 2007).

Having said that, some pioneers in the design community have offset the drawbacks of these two approaches, taking them together to explore the emotional states elicited in the product image. For example, Tomico et al. (2008) carried out a pilot study in order to explore the suitability of psychophysiological measures. They combined 2-point Electroencephalogram (EEG) and Repertory Grid Technique (RGT) interviews in order to measure the degree of comfort in terms of pleasantness and arousal (excitement). Jeskin et al. (2009) conducted a more rigorous experimentation for comparing Infrared Thermography (IRT), Electroencephalogram (EEG), and subjective measures of affective experience (ASR) to measure both cognitive and affective states.

Likewise, the present study also employs a mixed way: primary emotion by the physiological approach; secondary emotion by the cognitive-linguistic way. For the former, the Galvanic Skin Response (GSR) measure is applied and the latter for Self-Assessment Manikin (SAM) and twenty lexical terms (see Section 3 for detail).

The review of previous literature suggests that the product form in the early design process may play an important role in conveying the designer's intent (semantic and emotional). Thus, we developed the following two hypotheses:

- Hypothesis 1: Product forms in the early design process can generate emotional differences in the user's mind;

- Hypothesis 2: The emotional differences can be interpreted by conjoining both cognitive-linguistic and physiological way.

The following empirical study has been designed to address these two research questions and then how the emotional intents from the designer can be conveyed to the users via the product images at the earliest.

\section{Method}

To test the hypotheses above, a laboratory-based experiment was designed. Regarding a combination of cognitive-linguistic and physiological methods, we first employed a questionnaire developed by Mantelet (2006), which has been validated as a mean to identify and quantify the semantic and emotional responses to trend boards and product images. The questionnaire consists of the valence/arousal dimensions of the Self-Assessment Manikin (SAM), and 5-point rating scales for ten semantic descriptors and ten emotional terms. The rating scales of the questionnaire were then compared with Galvanic Skin Response (GSR) measures. 


\subsection{Participants}

A total of twelve French product designers took part in this experiment. The reason to employ only French product designers in the study was three-fold: i) to reduce the cultural issue only French-native speakers were invited to participate; ii) to significantly maximise the power of the sample size (i.e., 12), professional product designers were recruited instead of the general users that might not have sufficient experiences on early sketches; iii) we also assumed that most of design activities are made on the team-based, so the design team members should share the same emotional values from the design exercise.

The average number of years of experience was 6.6 years. The age of the participants is ranged from 23 to 41 years (average age $=29.4$ yrs.)

\subsection{Apparatus}

For the empirical study, ten low-fidelity sketches were collected. They were independently generated by other product designers as to "Designing Nike vacuum cleaner" (Authors, 2010). Initially, sixteen sketches were gathered, and the two external experts singled out ten quality sketches, as shown in Figure 3. All sketches were presented in a grey scale with a resolution of $1024 \times 768$.

Figure 3 Ten sketches selected for image stimuli (Design brief: Designing Nike vacuum cleaner)

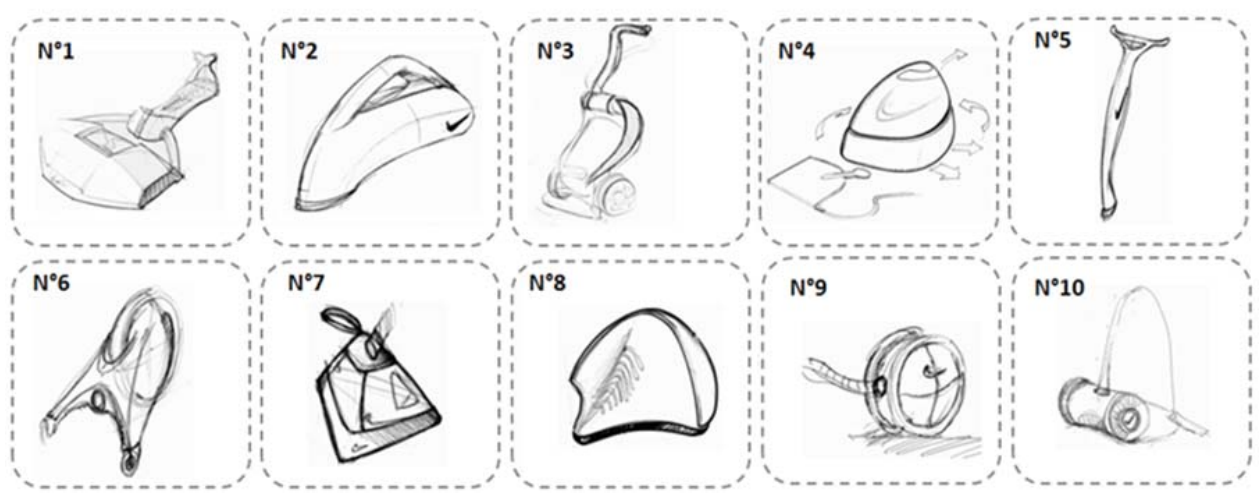

The Self-Assessment Manikin (SAM) scales by Lang (1997) were employed to reveal both valence (like or dislike feelings) and arousal (intensity of emotions). To establish the battery of ten emotional terms, a list of 20 emotional terms from the Geneva Emotion Research Group (1998) was given to the two independent experts. They chose the most relevant ten terms out of the twenty emotional terms. Regarding the semantic terms, our previous study had identified most relevant semantic descriptors of each design sketch (Authors, 2010), and these were reviewed by the two experts to choose ten most relevant items. Since 
all participants were native French, the lexical corpus was only set in French. Table 1 enlists the original French terms that were used in the empirical study and the corresponding translated English terms are given in brackets. The twelve participants were then rated each sketch (Figure 1) in five-point Likert scales (from $1=$ "not at all" to $5=$ "very much") on each emotional and semantic term.

Table 1 List of emotional terms and semantic descriptors: original French terms (translated English terms)

\begin{tabular}{|c|c|}
\hline 10 emotional terms & 10 semantic descriptors \\
\hline amusé (amused) & organique (organic) \\
stimulé (stimulated) & sympatique (appealing) \\
apeuré (afraid) & intelligent (intelligent), \\
enthousiasme (enthusiastic) & léger (light) \\
hésitant (hesitant) & sportif (sportive) \\
mal à l'aise (ill at ease) & masculine (masculine) \\
passionné (passionate), & moderne (modern), \\
serein (serene) & rapide (rapid), \\
supris (surprised), & dynamique (dynamic), \\
impressionné (impressed) & rigide (rigid). \\
\hline
\end{tabular}

\subsection{Procedure}

Figure 4 illustrates the experimental procedure adopted in the present study. Following the Lang's method (1997), each test began with a preparation slide that lasts 5 seconds. Then, each stimuli slide (i.e., sketches) was presented for 6 seconds. Finally, the participants were asked to rate each sketch in a rating slide. Each cycle of the test continued until all the sketches were assessed.

Figure 4 The experimental procedure used in the study

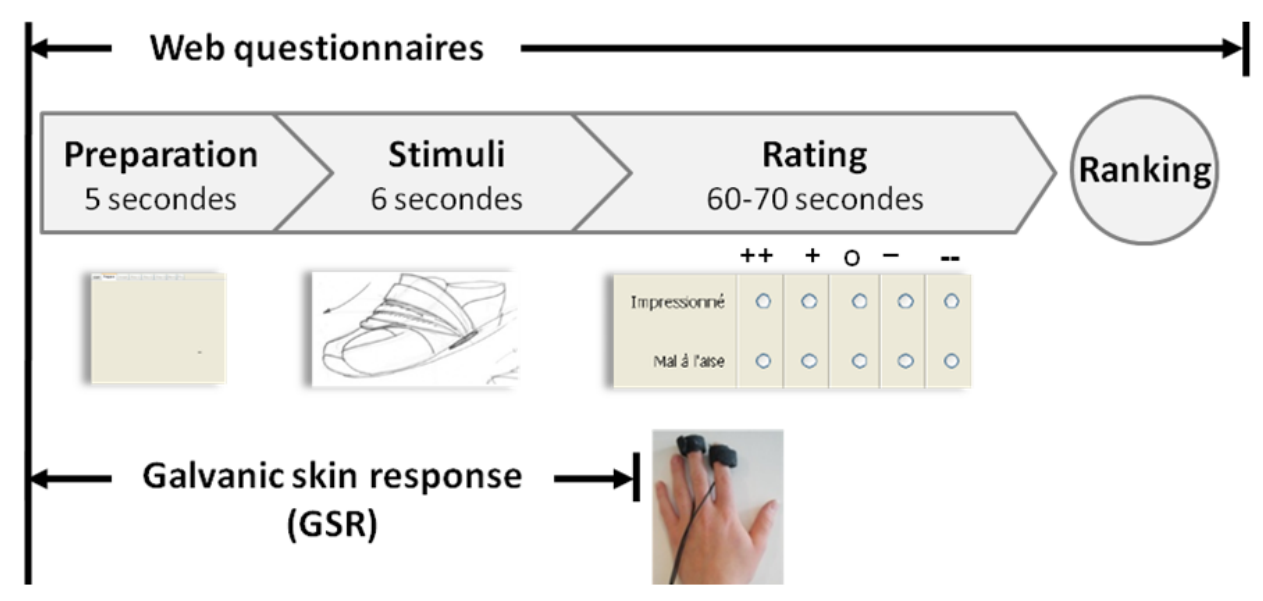


The one cycle of the test consisted of the following three slides (figure 4):

- The Preparation slide was a blank page in order for the participants to stabilise their emotional state before the main stimuli given;

- The Stimuli slide held each image stimulus (i.e., sketch) chosen in figure 3 ;

- The Rating slide consisted of three types of questions as described above. - The Self-Assessment Manikin (SAM)

- The list of 10 emotional terms to be rated on 5-point rating scales (see Table 1)

- The list of 10 semantic descriptors to be rated on 5-point rating scales (see Table 1)

In order to collect SCR (Skin Conductance Response), the two GSR electrodes were placed on two fingers (the second and third finger) of the left hand as shown in Figure 4. Changes in the skin conductance were collected at $200 \mathrm{~Hz}$ per second for 11 seconds, i.e., preparation slide (5 sec.) and stimuli slide (6 sec.) The GSR measures were analysed using BIOPAC acquisition unit and BSLPro 3.7.

On the Rating slide, a small thumbnail image was also presented for helping the evaluation process. At the end of the experiment, the participants were asked to rank the top three sketches, as an answer to the question "please rank from 1 to 3 the sketches being the most pertinent to the design brief Nike vacuum cleaner (ranking 1= most pertinent)”.

\subsection{Data gathering and analysis}

Principal Component Analysis (PCA) was applied to reduce multidimensional data sets of SAM, 10 emotional and 10 semantic terms. The Galvanic Skin Response (GSR) measures were analysed at peak and troughs of Skin Conductance Response (SCR) during the preparation and stimuli slides. However, thanks to individual differences in SCR latency and rise (Dawson et al. 2000), the original SCR values were normalised, i.e., normalised SCR value $=$ original SCR value/ maximum of SCR value, for the further analysis.

\section{Results}

The results are summarised in four subsections: Principal Component Analysis (PCA) of emotional terms, Skin Conductance Response (SCR) measures, PCA of semantic descriptors, and Ranking analysis.

\subsection{Principal Component Analysis (PCA) of emotional terms}

We first analysed the emotional terms used for assessing the sketches by PCA, as shown in figure 5. The contributions of the PCA sphere cumulated to $89.3 \%$ in 
the two first factors (F1 and F2). These principal axes can be interpreted as positive-negative valence and high-low arousal. Higher arousal ratings were observed in sketches N6, N8 and N5. In contrast, sketches N2, N10, and N9 were rated lower arousal loadings. High arousal was related to emotional terms such as 'impressed' and 'surprised'. In terms of valence, both N4 and N2 were positioned rightmost on the valence axis, which were highly linked with terms such as 'enthusiastic', 'passionate', 'stimulated' and 'amused'.

The PCA, in effect, points out that our participants perceived sketches N4, N5, N6 and N8 as positive and intensive. However, the higher valence of N2 was cancelled out by the lower rating in arousal.

Figure 5 PCA of emotional terms of Nike vacuum cleaner sketches: Positive valence group (enthusiastic, passionate, stimulated, and amused), High arousal (surprised and impressed)

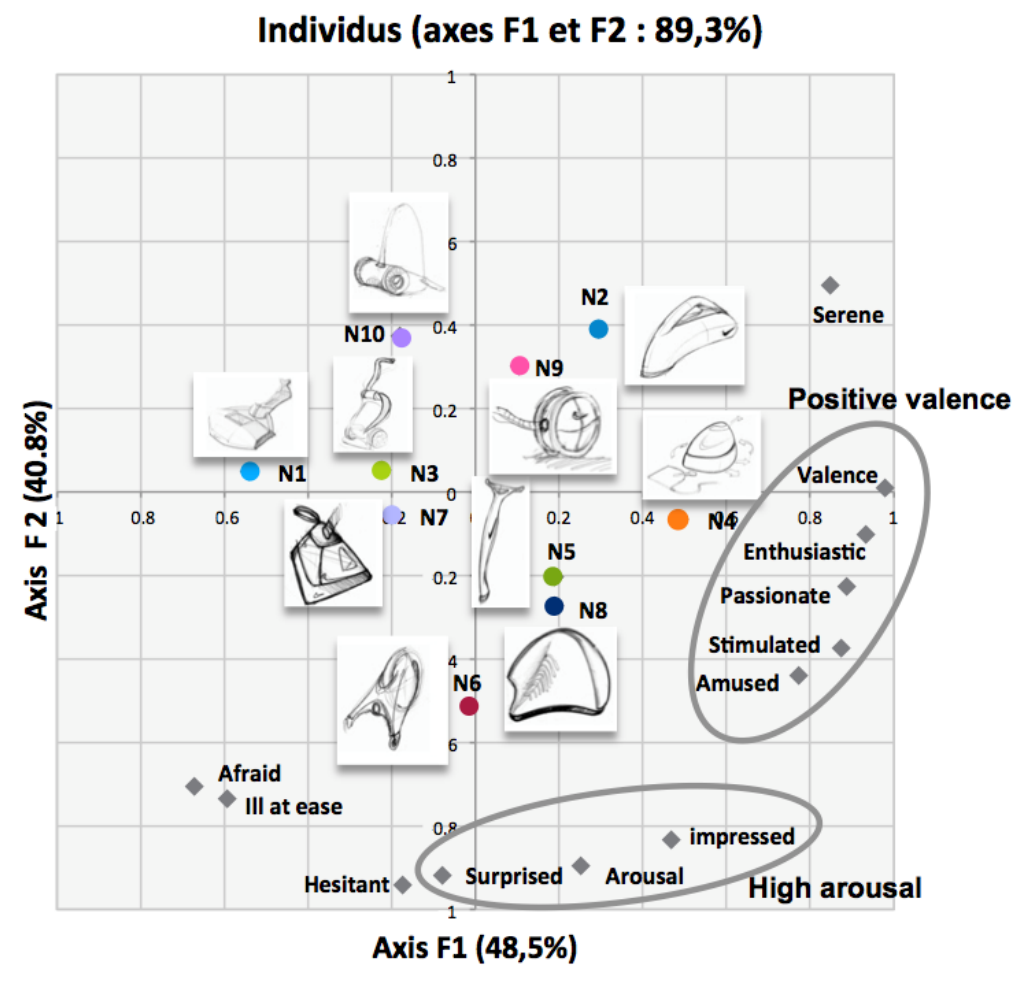

\subsection{Skin conductance response (SCR) measures}

Figure 6 depicts the normalised skin conductance response during 11 seconds (5 seconds for the preparation slide and 6 seconds for the stimuli slide as indicated in dotted line). The SCR measures were averaged out for the twelve participants. Like the results above, the SCR changes were higher in N8, N6, N4, and N5 (in order). It implies that they may elicit some higher emotional arousal than the 
other sketches. On the other hand, the sketches N1, N2, N3, and N10 did not show any remarkable changes between the preparation and the stimuli slide. It is supposed that they elicited some lower emotional arousal, which is also supported by the previous outcomes.

Figure 6 Change in the average normalized skin conductance response (SCR) during 11 seconds

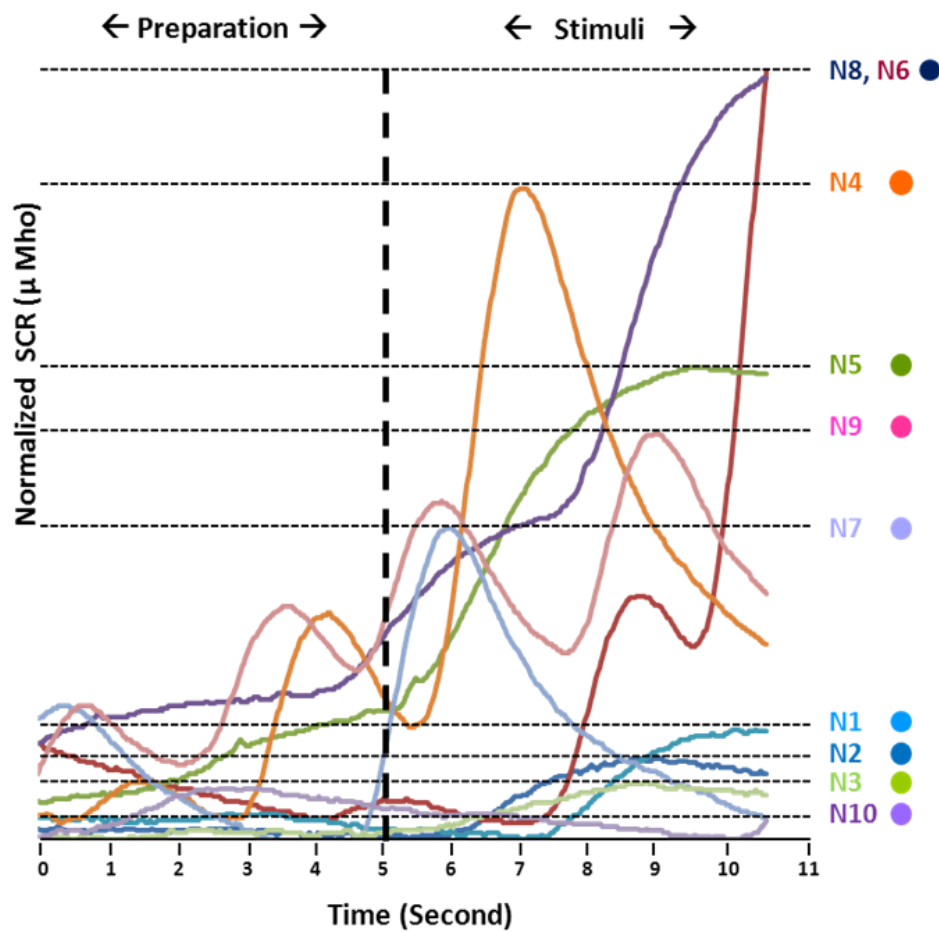

\subsection{Principal Component Analysis (PCA) of semantic descriptors}

The previous two results revealed that sketches N4, N5, N6, N8 would be highly differentiated in terms of the emotional dimension. However, N2 was somewhat mixed, that is it was low arousal but high valence. This perhaps comes from the fact that quality of design should be assessed by the "ideal" vision of "Nike vacuum cleaner", which needs to be analysed in the semantic dimension of the sketches.

That said, we again applied PCA analysis for the semantic descriptors of the ten sketches (figure 7). Given that the cumulative contribution of PCA showed the correlation between semantic descriptors, the contributions were focused on the first two axes F1 (55.2\%) and F2 (31.2\%), for a total contribution of 86.4\% for the two principal factors. There are two groups of semantic descriptors as shown in figure 7. While sketches N4 and N8 have close semantic features related to 'appealing' and 'organic', and sketches N2, N5, and N6 were semantically closed to one after another, as being 'modern', 'rapid', 'dynamic', 
'sportive' and 'light', which might well reflect the ideal vision of "Nike vacuum cleaner',

The results, in effect, figured out that N2 seems to be highly appraised in terms of the ideal vision of Nike vacuum cleaner, and this can be separated out from the analysis of the emotion dimension.

Figure 7 PCA of semantic descriptors of Nike vacuum cleaner sketches: Semantic group 1 (appealing and organic), Semantic group 2 (light, modern, rapid, dynamic, and sportive)

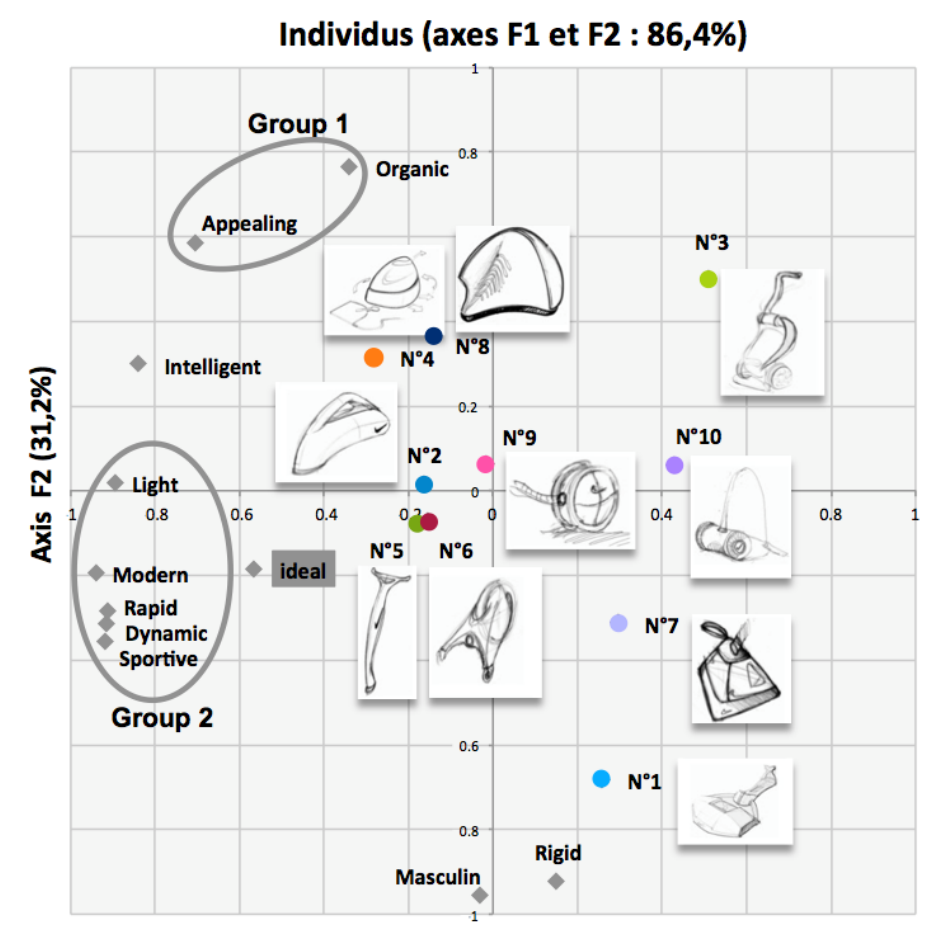

Axis $\mathrm{F} 1(55,2 \%)$

\subsection{Ranking analysis}

Figure 8 shows the sum of the ranking points with weighted ranking values. That is, we assigned points from 1 to 3 according to the rank for example, rank $1=3$ points, rank $2=2$ points, and rank $3=1$ point.

Based on this analysis, we observed that the N4 and N2 got the highest score; the N5, N8 and N9 followed. Interestingly, we found that there was a disagreement in their ranking; for instance, most of the designer did not choose the N2 and N4 as their preference simultaneously. This result implies that those sketches were perceived differently by participants and had very distinct features that can express what would be a good "Nike vacuum cleaner". 
In conjunction with both the emotional and semantic dimension, N2 and N4, N5, N6, and N8 were highly recognised by our participants.

Figure 8 Ranking analysis

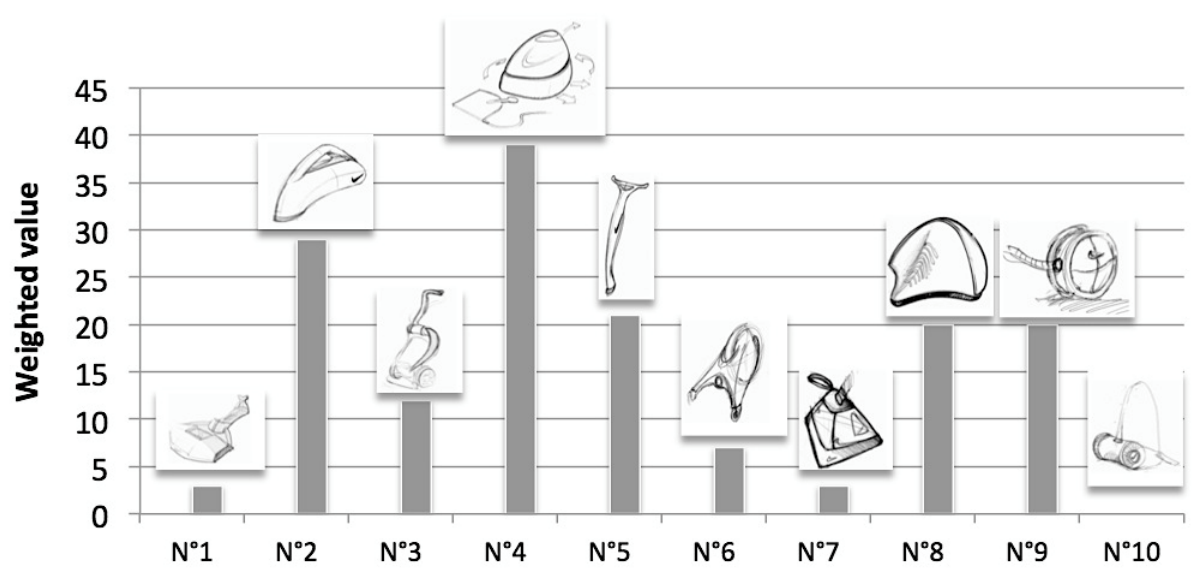

\section{Discussion}

Based on the results described above, it seems that using both cognitive and physiological approaches would yield more accurate, simultaneous, and objective results. We further discuss the two hypotheses raised in section 2 and some of the methodological limitations.

5.1 A mixed approach to specify emotion in product images: Cognitivelinguistic and physiological methods (Hypothesis 2)

Concerning Hypothesis 2, our empirical study showed that the combination of the cognitive-linguistic (questionnaire) and physiological method (GSR) allowed us to quantify emotional responses to early sketches. That is, the physiological measures would be quick to detect the arousal of the product image, but it cannot tell what makes this arousal in the product image. In contrast, the questionnaire method would be able to account for what emotional annotation could be associated with that emotional arousal.

Though the mixed approach would be able to detail emotional impacts of a product image given, some of the early sketches were hard to convey the designer's emotional intents through their product images. For instance, sketches N1, N3 and N10 elicited lower emotional arousal in both questionnaire and SCR measures. This means that these sketches were not able to deliver the emotional intents of the designer, if it was what they meant. Hence, it can be seen that the users could not share the same emotional impacts. This mixed approach thus can 
be easily applied in the early design stage to quickly detect whether or not the designer's emotional intents are conveyed to the user.

A positive correlation between the arousal of Self-Assessment Manikin (SAM) and changes of SCR has already been identified in a study on mobile phone design (Mahlke and Minge, 2008). Though most of previous studies employed relatively high fidelity prototypes to see the emotional differences (perhaps it might come from colours and so forth), the present study used a low fidelity prototype, which has not been empirically demonstrated before. Indeed, the early sketches do not have many design attributes such as colours or material texture, so it is lesser used in the study of emotion. However, our study contributed that this early detection mechanism is possible with the mixed approach proposed in the whole design cycle.

\subsection{Incorporating emotional impacts of early product image in the whole design process (Hypothesis 1)}

As discussed above, the main contribution of the present study is to show how the mixed approach (SCR and questionnaire) can quickly detect the possible emotional impacts on the users along with early sketches. This is crucial in the design exercises in that this makes the whole design process much agile. Of course, our empirical study also showed that emotional impacts from product images are not the unique determinant of good design. The semantic impacts from product images are also crucial to perceive the product image.

This stance would further justify our mixed approach in conjunction with semantic descriptors. Take the example of the sketches N2 and N4, which were both highly ranked in the ranking analysis, but provoked a distant level of arousal. This emotional difference was understood as their different semantic features based on the results from PCA analysis of semantic descriptors. For instance, the sketch N4 was more appealing and organic, while the sketch N2 was more modern, rapid, dynamic, and sportive. This finding suggests that the emotional differences of product images would be also generated by semantically different product forms. It would help designers to define design specification (sematic features) on account of the different emotional values anticipated. Hence, the Principal Component Analysis (PCA) of emotional responses and Skin Conductance Response (SCR) changes would allow us to identify the different kinds of semantic and emotional responses to early sketches, including both primary and secondary emotions.

In addition, since every design activity is no longer an individual work, the awareness of the emotional impact of design solutions can help the designer herself and other collaborators involved in the early design process to share the emotional impact and communicate better with one after another. Indeed, constantly checking emotional values of the product image as a core part of user testing would be interesting to evolve the design concept and better reflect the user's perception from the product image. 


\section{Lesson learnt and further study}

In this study, we initially raised the research question about "how designers are able to manipulate the emotional impact of their design solutions, and how these solutions are perceived by the user'. Hence, we focused on the early sketches. The results demonstrated that early sketches can sufficiently express designer's own semantic and emotional attributes. In particular, a 'good form' of sketches can elicit a positive feeling (valence) and a higher arousal state. In addition, we proposed a method combining cognitive and physiological approaches, including a web questionnaire and Galvanic Skin Responses (GSR). It enabled us to quickly check the emotional impacts and specify them with secondary emotional terms.

However, unlike what we have assumed, some participants had shown emotional detachment with early sketches, focussing on the semantic meaning of the ideal of the design. Indeed, this is very natural in any design practices, and both emotional and semantic design should work together for the final product image. Therefore, simply a product image with lesser emotional impact should not be undermined, but our claim in this article was to see how emotional impacts can be immersed at earliest in the whole design process.

Another limitation of the current study was not to involve the actual user group. In fact, this was deliberate to present stronger evidences and the designer would be more sensitive to the early sketches. However, to claim the way how the emotional impacts of the designer is transported to the user, it is still necessary to include the representative users, which is planned to carry out in the near future.

Finally, the apparatus used in the empirical study might constrain our interpretations. Though the web-based questionnaire method enabled an instant data collection the designer might be sensitive to sketches on a paper rather than on the screen. Furthermore, all sketches were presented in a single size on the screen $(1024 \times 768$ resolutions), which might overlook the actual size of the product. For instance, the sketches of 'Nike vacuum cleaner" involved various types of vacuum cleaners: small hand-held types (N2, N5), robotic types (N4, N7, and N8), an upright type (N3), canister types (N6, N9, and N10), and others (N1). We noticed that relatively big-size vacuum cleaners, such as an upright type and a canister type cannot sufficiently express their own semantic and emotional attributes in a given experimental condition. The results might suggest that smallsize vacuum cleaners, e.g., N2 and N5, have higher semantic and emotional response, in this respect. All these limitations would be fully addressed in a subsequent study.

\section{References}

Artacho, M.A. Ballester, A. and Alcantara, E. (2010) 'Analysis of the impact of slight changes in product formal attributes on user's emotions and configuration 
of an emotional space for successful design', Journal of Engineering Design, Vol.21, No. 6, pp. 693-705.

BIOPAC (2010) 'Biopro 3.7.’ Computer software, http://biopac.com

Bloch, P.H. (1995) 'Seeking the ideal form: Product design and consumer response’, Journal of Marketing, Vol.59, pp.16-29.

Authors (2010)

Authors (2011)

Chuang, Y. and Chen, L. L. (2008) 'How to rate 100 visual stimuli efficiently' International Journal of Design, Vol.2, No.1, pp.31-43.

Crilly, N. Moultrie, J. and Clarkson, P.J. (2004) 'Seeing things: consumer response to the visual domain in product design’, Design studies, Vol.25 No.6, pp.547-577.

Crilly, N. Moultrie, J. and Clarkson, P.J. (2009) Shaping things: intended consumer response and the other determinants of product form. Design studies, Vol.30, No.3, pp.224-254.

Cuisinier, F. (2010) 'Emotions and design between feelings and emotions', $A R T+D E S I G N / P S Y C H O L O G Y$, Vol.2, pp.49-56.

Dawson, M. E. Schell, A. M. and Filion, D. L. (2000) 'The electrodermal system', in Cacioppo, J. T. Tassinary, L. G. and Berntso, G. G. (Eds). Handbook of psychophysiology (2nd Ed., pp. 200-223), Cambridge, UK: Cambridge University Press.

Desmet, P.M.A. and Dijkhuis, E. A. (2003) 'Wheelchairs can be fun: a case of emotion-driven design', Proceedings of the International Conference on Designing Pleasurable Products and Interfaces, 23-26 June 2003, Pittsburgh, Pennsylvania, USA. New York: ACM publishing.

Desmet, P. M. A., and Hekkert, P. (2007) 'Framework of product experience', International Journal of Design, Vol.1, No.1, pp.57-66.

Ekman, P. (1992) 'An argument for basics emotions', Cognition and emotion, Vol.6, No.3/4, pp.169-200.

FEEL EUROPE (2008) 'Vision paper', Available from: from http://www.feeleurope.org/VisionPaper.pdf. [Accessed 14 Sept 2010].

Ganglbauer, E. Schrammel, J. Deutsch, S. and Tscheligi, M. (2009) 'Applying Psychophysiological Methods for Measuring User Experience: Possibilities, Challenges and Feasibility', UXEM'09.

Geneva Emotion Research Group (1998), 'Appendix F.Labels describing affective states in five major languages.' In Scherer, K. R. (Ed.) Facets of emotion: Recent research (pp. 241-243). 
Hardré, P.L. Crowson, H.M. Xie, K. and Ly, C. (2007) 'Testing differential effects of computer-based, web-based and paper-based administration of questionnaire research instruments', British Journal of educational Technology, Vol.38, No.1, pp.55-22.

Helander, M. G. and Khalid, H. M. (2006) 'Affective and pleasurable design', Handbook of human factors and ergonomics, pp.543-572.

Hsiao, S.W. and Wang, H.P. (1999) 'Applying the semantic transformation method to product form design’, Design studies, Vol.19, No.3, pp.309-330.

Hsiao, S.W. and Huang, H.C. (2002) 'A neural network based approach for product form design’, Design studies, Vol.23, No.1, pp.67-84.

Hsiao, S.W. and Liu, M.C. (2002) 'A morphing method for shape generation and image prediction in product design’, Design studies, Vol.23, No.6, pp.533-556.

Hsiao, S.W. and Tsai, H.C. (2004) 'Use of Gray System Theory in product-color planning’, Color Research and. Application, Vol.29, No.3, pp.222-231.

Hsiao, S.W. Chiu, F.Y. and Liu, S.H. (2010) 'Product-form design model based on genetic algorithms', International Journal of Industrial Ergonomics, Vol.40, No.3, pp.237-246.

Ho, A.G. and Siu, K.W.M. (2009) 'Emotionalise design, Emotional Design, EmotionDesign: A new perspective to understand their relationships', Proceeding of IASDR 2009.

Jenkins, S.D. Brown, R.D.H. and Rutterford, N. (2009) 'Comparing thermographic, EEG, \& subjective measurement of affective experience during simulated product interactions', International journal of Design, Vol.3, No.2, pp.53-65.

Jindo, T. Hirasago, K. and Nagamachi, M. (1995) 'Development of a design support system for office chairs using 3D graphics', International Journal of Industrial Ergonomics, Vol.15, pp.49-62.

Lang, P.J. Bradley, M.M. and Cuthberth, B.N. (1997) 'International affective picture system (IAPS):Technical Manual and Affective ratings', NIMH Center for the Study of Emotion and Attention.

Lévi, P. Lee, S.H. and Yamanaka, T. (2007) 'On Kansei and Kansei Design: A description of Japanese design approach’, Proceeding of IASDR, Seoul, South Korea.

Mahlke, S. and Minge, M. (2008) 'Consideration of Multiple Components of Emotions, Human-Technology Interaction'. Affect and emotion in humancomputer interaction, Vol.4868, pp.51-62.

Mantelet, F. (2006) Prise en compte de la perception émotionnelle du consommateur dans le processus de conception de produits. Ph.D Thesis, Arts et Metiers ParisTech, France. 
Nagamachi, M. (1989) Kansei Engineering, Kaibundou, Tokyo.

Nagamachi, M. (2001) 'Workshop 2 on Kansei engineering', Proceedings of the International Conference on Affective Human Factors Design, CAHD 2001, London: Asean Academic Press.

Norman, D.A. (1988) The Design of Everyday Things, New York: Basic Books.

Norman, D.A. (2004) Emotional Design: Why We Love (or Hate) Everyday Things, New York: Basic Books.

Overbeeke, C.J. and Hekkert, P. (Eds.), (1999) Proceedings of the first international conference on Design and Emotion, Delft: Department of Industrial Design.

Plutchik, R. (1980) Emotion: A psychoevolutionarysynthesis, New York: Harper \& Row.

Russell, J. A. (1980) 'A circumplex model of affect'. Journal of personality and social psychology, Vol.39, No.6, pp.1161-1178.

Schütte, S. (2002) Designing Feelings into Products: Integrating Kensei Engineering Methodology in Product Development, Ph.D. Thesis, Linköpinh.

SEAT Project D1.1 (2006) Physiological Monitoring and Cabin Comfort, FP6AST5-CT-2006-030958 SEAT.

Suwa, M. and Tversky, B. (1997) 'What do architects and students perceive in their design sketches? A protocol analysis', Design Studies, Vol.18, No.4, pp.385-403.

Tomico, O. Mizutani, N. Levy, P. Yokoi, T. Cho Y. and Yamanaka, T. (2008) 'Kansei physiological measurements and constructivist psychological explorations for approaching user subjective, experience', International Design Conference, Dubrovnik.

Tran, T. Q. Boring, R. L. Dudenhoeffer, D.D. Hallbert, B.P. Keller, M.D. and Anderson, T.M. (2007) 'Advantages and disadvantages of physiological assessment for next generation control room design'. Human Factors and Power Plants and HPRCT 13th Annual Meeting, Monterey, CA, USA.

Wang, H. (1995) 'An approach to computer-aided styling', Design Studies, Vol.16, No.1, 50-61. 